\title{
PROMINENCE AND MEANING SELECTION IN GHANAIAN ENGLISH DISCOURSE: TOWARDS A CATEGORIZATION OF THE NEW ENGLISHES
}

\author{
Charlotte Fofo Lomotey \\ University of Education, \\ Winneba, Ghana
}

\begin{abstract}
:
All models of intonation recognize that speakers in any communication context select prominence based on their communicative intents. Consequently, every prominent syllable bears a specific communicative function. However, while prominence selection appears fixed in inner circle Englishes, the same cannot be said of outer (OC) and expanding circle (EC) Englishes. Results from research clearly suggest that it is not always possible for OC and EC speakers to select prominence to indicate meaning selection. This study reports findings on the selection of prominence in Ghanaian English in relation to Brazil's Discourse Intonation model. Data consisting of 6 hours of English conversations from 100 Ghanaians were analyzed using Brazil's model. Results show that just as in other OC English varieties, Ghanaians assign prominence to individual syllables with communicative intent, although their selections may not always coincide with the functions proposed in Brazil's model. Based on these results, it is argued that rather than being viewed as deficiencies, phonological choices such as prominence selection should be regarded as common to OC Englishes. The study, therefore, argues for an adoption of a model that describes the intonation of outer circle Englishes in relation to their contexts and not on a native speaker model.
\end{abstract}

Keywords: prominence, meaning selection, Ghanaian English, outer circle Englishes

\section{Introduction}

The English language has seen a phenomenal expansion across the globe such that its speakers have been grouped into three: inner circle, outer circle, and expanding circle (Kachru, 1986). According to Kachru, inner circle speakers are those who use English as a native language; outer circle speakers use it as a second language, while expanding circle speakers use it as a foreign language. While inner circle speakers are seen to use the language for specific functions or purposes, the same cannot be said of those outside of it. For example, research results suggest that speakers of outer circle Englishes (e.g. Ghanaian English, Nigerian English, Indian English) markedly differ from inner circle speakers in the use of phonological features, especially with regard to prosody. Prosodic features include stress (and prominence), rhythm, and intonation.

i Correspondence: email cefolatey@yahoo.com 
The present study examines the role of prominence in meaning selection in Ghanaian English. Specifically, it investigates how speakers of Ghanaian English make meaning through prominence selection and how this selection affects communication with other speakers of English.

Whenever we speak, we use different cues or features to convey our communicative intentions. These features may be morphological, syntactical, and phonological (or prosodic). In English, prosodic features such as duration (or length), pitch, and amplitude (or loudness) are combined to mark prominence (c.f. Selkirk, 2002). Prominence is usually marked to communicate to the listener that they should pay attention to that particular syllable word or that there is important information being carried by that syllable. Thus, the communicative intention of the speaker allows him or her to choose which syllables to mark as prominent (Brazil, 1997). Prominence plays significant roles in the way information is packaged both at the sentence and discourse levels. In this study, prominence is a prosodic entity that involves pitch change. In fact, Brazil et al. (1980) define prominence as a property that is associated with a word by virtue of its "function as a constituent of a tone unit" (p. 39). Tench (1996) also explains it as the combination of pitch, duration, and intensity, and that it is the highest pitched syllable with the greater pitch movement within a given intonation unit. It can therefore be described as the change in stress, pitch or emphasis that allows for added meaning to be inferred from a speaker's utterance. As prominence determines the salience of syllables, a speaker decides on which one s/he assumes to be crucial to his or her communicative intent and marks it as meaningful. The function of prominence discussed in this paper is taken to be pragmatic, rather than semantic or syntactic. The next section describes the concept of prominence and how it might affect meaning selection in English. The third section discusses Discourse Intonation, the theoretical framework adopted for the study and presents an overview of how speakers assign prominence to select meaning. The fourth section presents the methodology, followed by a discussion of results in the fifth section. The final section presents the conclusion of the study.

\section{Prominence marking and meaning selection in English}

As already indicated, we observe that speakers make some syllables more prominent than others depending on their intentions. As a result, a prominent syllable is mostly indicated as the one that stands out from among all the other syllables within the tone unit. For example, Terken and Hermes (2000) define prominence as a property of a linguistic entity relative to an entity or a set of entities in its environment. Therefore, a prominent syllable is one that is seen to be produced with 'more effort' than the surrounding syllable(s). In essence, speakers highlight certain syllables to show prominence in order to make meaningful choices (Brazil, 1978). For instance, Brazil (1978) again argues that, "very informally, we might say that the presence of a prominent syllable is a signal that the word must be attended to; the absence of prominence indicates that it is informationally superfluous" (p. 55). The 'effort' that a prominent syllable can be produced with can be higher amplitude, longer duration, higher pitch, or a combination of any of these cues.

Because prominence can perform pragmatic functions, Dalton and Seidlhofer (1994) observe that, 
"Prominence ... is to a large extent a matter of speaker choice: it is an indication as to what the speaker wants to make salient in the conversational discourse, a reflection of how he or she views the state of conversational play." (pp. 54-55)

This suggests that a speaker's pragmatic intentions may lead him/her to decide which syllables to assign prominence. The speaker thus decides how many syllables to highlight in a tone unit to achieve their communicative intent. This decision also determines whether there is only one or more stressed syllables within the tone unit (Crystal, 1969). This assertion is captured in Low (2015), who intimates that "important information is not carried via unstressed syllables, while some important information is not carried via stressed syllables, but the most important information is carried via accented syllables and they also constitute the nucleus of the sentence" (p. 90).

Although prominence bears specific communicative functions in utterances in inner circle Englishes, the same cannot be always said of outer circle Englishes. For instance, Goh (2000) observes that although Singaporeans assign prominence to words to signal new information, they also have a tendency to make nonselective words prominent. She provides an illustration in Example 1:

\section{//in Egypt// STOry TELLing pictures// have been FOUND// on BUILdings and TOMBS//} (p. 4)

In 1 , Goh notes that the last word in each final tone unit - tombs, sound and ambiguity are all choices made from a possible range of words. She goes further to explain that the speaker highlights the word tombs, to draw listeners' attention to a particular location as opposed to other possible ones such as gardens or houses.

In the same study, Goh exemplifies the prominence assigned to non-selective words as in

2:
A: //what is IT//

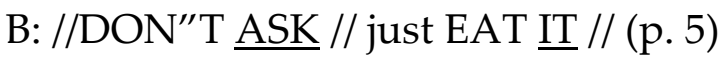

With this, she reiterates that while eat carries significant communicative value representing an action B wants to take, B does not highlight it; rather, he chooses it, although it is non-selective and therefore cannot receive prominence.

We realize from the examples that prominence is sometimes selected appropriately and sometimes inappropriately. Meanwhile, this is an essential or core feature in Jenkins' (2000) Lingua franca core (or LFC), meaning that it contributes to intelligibility and so must necessarily be produced by speakers of English as a lingua franca (ELF). As such, its misplacement can seriously affect comprehensibility, especially when communicating with inner circle speakers (Hahn, 2004; Warren et al, 2009). Tench (1996) also notes that if speakers do not appropriately select words, the pragmatic value of the utterance may be obscured, leading to difficulty in processing and ultimately result in miscommunication. This clearly shows that it represents a significant area of difference between outer circle and inner circle Englishes (c.f. Goh, 2000, 2001; 
Levis, 2005; Low, 2000). Levis (2005), for example, opines that there is an almost complete absence of final de-accenting in Singapore English, and this suggests that "the prominence system of $S g E$ is structured differently from AmE" (p. 91). From this, he argues that such differences have also been identified in other Outer Circle varieties of English, suggesting that such tendencies are very common among ESL speakers.

It is important to note that while studies have been conducted on some outer circle English varieties, for instance, Singapore English (Levis, 2005; Goh, 2000, 2001) and Malaysian English (Goh, 2001), there is no known study to examine and reveal how speakers of Ghanaian English mark select prominence in communicating meaning. Such a study would enable us to understand the relationship between prominence and meaning selection in discourse and how it affect listeners' comprehension. Ultimately, the results contribute to on-going discussions of the linguistic features of ESL varieties which lead to a better understanding of Englishes around the world. To achieve this, the following objectives of the study are:

1) to determine how speakers of Ghanaian English use prominence to convey their communicative intentions during interactions;

2) explore the role of prominence in meaning selection in outer circle Englishes.

Based on the objectives, the following questions have been formulated to guide the study:

1) how do speakers of Ghanaian English use prominence to convey their communicative intentions during interactions?

2) what is the role of prominence in meaning selection in outer circle Englishes?

\subsection{Theoretical framework: Discourse intonation and prominence selection}

Discourse intonation is the framework adopted for the present study and is used in investigating the functions of intonation in discourse. This model was proposed by Brazil $(1985,1997)$, and was influenced by the works of others (e.g. Brazil et al., 1980; Sinclair \& Brazil, 1982; Sinclair \& Coulthard, 1975). Brazil views the discourse approach to the study of intonation as a crucial one because he notes that intonation carries significant communicative and pragmatic functions as far as understanding messages is concerned. In this approach, the choices speakers make are linked to the communicative value of the interaction between the speaker and the hearer. With reference to this approach, Brazil (1995) suggests that, "the communicative value of intonation is related to the purpose that a particular piece of language is serving in some ongoing, interactive event" ( $p$. 240). Thus, discourse participants reflect on the understanding they share to show the relationship between an utterance and its communicative value. Brazil has therefore proposed a model to explain the interpretation of the intonation choices participants make in the conversation.

Participants in an interaction use the different intonation choices they make to achieve their communicative values, thus making communication a "purpose-driven activity whereby speakers and hearers co-operate to reach the goal of shared understanding" (Hewings, 1995, p. 61). A speaker's assumptions and intentions are premised on "the shared ground between speaker and hearer" (Cauldwell \& Allen, 1999, p. 12). This shared ground, as well as the understanding arising from speakers' assumptions and intentions, depends largely on the context of interaction. This context of interaction is determined by the real-time assessment of shared and unshared 
knowledge between the speaker and hearer. In effect, all intonation choices are tied to the context in which they occur to show their 'present' communicative value, as Brazil (1995) observes that, "only if we regard intonation as a 'situation-creating' device ... can we give proper recognition to its ability to carry independent meanings" (p. 238).

From Brazil's observation, the use of any of the systems, for example, tone or prominence depends on what context of interaction speakers choose to project. It thus suggests that it is impossible to isolate a stretch of speech from its context, and hence, make reasonable generalizations about intonational meaning. Due to the changing nature of context, speakers make intonation choices that speakers make are "the moment-by-moment context-referenced choices" (Cauldwell, 2007, p. 5), and these are relevant only at the time of speaking to suit that particular moment, while they continuously assess the relationship between the message and the hearer. This assessment allows participants to negotiate both shared and new information, as well as contribute to the smooth flow and the understanding of the discourse.

Discourse intonation works with a small and finite number of choices that speakers select from. This selection is made within the tone unit, a minimal unit of analysis. A tone unit is a "stretch of language that carries the systematically-opposed features of intonation" (Brazil, 1997, p. 3). The feature opposition means that there are at least two entities that speakers can always choose from; they cannot choose both, but only can be selected. Typically, there are two syllables; one prominent and one non-prominent. These syllables typically define the boundaries of the tone unit. In discourse intonation, a tone unit can comprise three parts: an optional proclitic segment, a mandatory tonic segment, and an optional enclitic segment. The tonic segment contains the tonic syllable, and Brazil observes that it may usually contain at least one additional prominent syllable that speakers may select based on their pragmatic intentions. In Brazil's model, prominence involves pitch change, and is it is defined by Brazil et al (1980) as a property that is associated with a word by virtue of its "function as a constituent of a tone unit" (p. 39). They further argue that speakers make syllables prominent because they want to make meaningful choices within the discourse.

The choice to mark prominence on some syllables depends on their communicative needs and the existential paradigm. This paradigm is "a set of assumptions which are experientially linked in a certain context" (Coulthard, 1994, p. 255). Based on these assumptions, speakers choose a prominent syllable "... for present purposes, to be the state of understanding between him/her and a hearer" (Brazil, 1997, p. 132). For instance, in Example 3,

(i) // a pack of PENS is on the CHAIR //

(ii) // a PACK of pens is in the CHAIR //

In (3), the speaker marks pens as prominent in (i) as against, for instance, pencils and also shows the location by selecting chair instead of table. In this sense, the speaker chooses these to project a situated context in which both pieces of information are unrecoverable based on prior interaction (and, therefore, new). This is why s/he did not choose 'bunch' of books and 'sit' to communicate meaning. Again, the choice of pack in (ii) shows that in this situation, pens has 
already been mentioned, so it can be recovered. With this, it is not possible for the hearer to assume that other choices are possible within the existential paradigm.

A prominent syllable can be the onset or the tonic syllable. In Brazil's model, the onset syllable is the first in the tone unit while the tonic syllable is the last. Brazil notes that there can be situations where there can be intermediate prominent syllables between the onset and the tonic, although those with one or two prominent syllables are usually the norm. The tonic syllable is as "the place at which a significant pitch movement or tone begins" (Brazil, 1994, p. 8). As already indicated, every tonic syllable performs a particular function as it "form[s] the focus of information: to express what the speaker decides to make the main point or burden of the message" (Halliday, 1970, p. 40). The tonic syllable carries the tone; as such, once it occurs in the tone unit, the tone also occurs. This fact is confirmed by Cheng, Greaves and Warren (2008) that "a tone unit is complete when a tone has occurred, and there can be one tone per tone unit" (p. 16). The tone choice that speakers make can be falling, rising, or level. While the falling tone is chosen to project information as new, the rising tone is chosen to project it as given or recoverable with the level tone used to project no particular communicative value.

Almost all the choices that speakers make are made on the tonic syllable since it forms the focus of the information in the tone unit. In addition to containing tone choices, it is also responsible for termination selection. Termination is the pitch height on the tonic syllable. Similarly to tone choice, termination choice can be high, mid, or low and each of these has a particular function it performs. Every tone choice made also projects a particular communicative value. In essence, prominence allows speakers to make selections that convey specific messages and subsequently create meaning in order for their listeners to understand the communicative import of the message.

\section{Material and Methods}

This section presents the methodology adopted for the study. The discussion focuses on the research approach and design, sample, data instruments and collection, and data analysis.

\subsection{Research approach and design}

Qualitative research approach was employed to guide in selecting instruments and in data collection. Denzin and Lincoln (2018) note that a qualitative research approach provides a deeper analysis and allows the researcher to show a richer and an in-depth understanding of how people make meaning of their situation or interpret phenomena. Since the study involves the identification and interpretation of intonational patterns, a case study design was chosen. A case study is one in which the researcher makes in-depth analysis of a case or one or more individuals through the use of a variety of data collection procedures (Yin, 2009). A case study was therefore chosen in order to reveal in detail, the discourse intonational features that speaker of Ghanaian English produce in real-life situations. 


\subsection{Sample}

The sampling techniques used were purposive and snowball. With regards to the purposive sampling, the participants were selected based on their knowledge and experience of the phenomenon studies. The participants were graduates of either the three-year SHS programme or the four-year SHS programme. This way, they have knowledge regarding the topics for the discussion and could provide enough information while also making English intonational choices as to the use of prominence, tone, and pitch. These students were chosen for three (3) reasons: One, they represented and studied Ghanaian languages studied in school which constitute about $96 \%$ of the entire population of Ghana. The languages are Akan, Ewe, GaDangme, Nzema, Dagbani, Gonja, Dagaare, Gurene, and Kasem. Because of their language composition, the participants can be described as being representative of all educated Ghanaians. Two, they were chosen based on the fact that they had received instruction in English from age 6 to at least age 22 and were using the language for diverse purposes (for example, class discussions, conversations, group work). As such, they could read and engage in discussions because majority of them were more proficient in English than those in the senior high schools; and Three, they were selected because they all studied only Ghanaian languages and no student of English or French was included. This was to prevent a carry-over of the knowledge of English or French intonation systems or functions into their conversations. This was important to ensure that only Ghanaian English intonational features would be produced.

It was not possible to locate all the students because the researcher was an outsider at the time of the data collection. As such, snowball sampling technique was employed to help trace them. According to Creswell (2012), snowball is one that "typically proceeds after a study begins and occurs when the researcher asks participants to recommend other individuals to study" (p. 209). Thus, referrals are made among people who know others who share characteristics that are of interest to the researcher. With this, the first group of students that were contacted also contacted their friends who willingly took part. This continued until all the participants were obtained. In all, 100 participants from a public university in Ghana were recruited for the study. This comprised 50 males and 50 females for the purposes of gender balance and their ages ranged from 18 to 40 years. All participants were fluent in their native language and used and continue to use English as a second language. This information was obtained with the use of a short questionnaire on their biographical data. They all indicated that they started learning English when they entered school at age 6; that is, after they had already started speaking their native languages.

\subsection{Data instruments and collection}

The instruments for the study were recorded discussions in the form of conversations. These were based on current topical issues; the SHS duration in Ghana. Conversations are interactive and usually spontaneous in nature, and mostly tend to focus on a particular subject or topic. For example, Clark (2001, p. 2744) suggests that conversations are "social creations which are produced as participants coordinate with one another to succeed". Besides coordinating with one another, what participants say is usually not predetermined but emerges as they negotiate their way through the activities they carry out. In relation to this, Clark and Schaefer (1989) also emphasize that conversations can only succeed when participants ground what they say. In other words, they 
have to establish the mutual belief that the hearer understands the speaker well enough for current purposes, usually, by forming an adjacency pair. In conversations, as opposed to read speech, participants engage in natural interactions and utilize certain prosodic features including intonation and speech rate to achieve mutual understanding (Samuelsson, 2009). Since this investigation centred on the use of intonation in discourse in typical Ghanaian English, no constructed dialogues are used. These conversations were therefore produced in situational contexts set up by the researcher and were considered appropriate for a study of this nature.

The participants were 18 years and above, as such, their consent was sought directly from them. Participants were put into 20 groups with five (5) people in a group once they gave their consent to be part of the study. Each group represented a language group, making sure that no speakers of more than one language were put together. Each group was made to sit around a big conference table in a quiet room and given the discussion prompt to study. This prompt was on a recent national educational issue (at that time) which was of interest to all Ghanaians, but of more interest to the students because they were better placed to share their experiences (the discussion prompt is found in the appendix). Every participant took part voluntarily, without any coercion or promise or enticement. Once they indicated that they were okay with the prompt, they were alerted of the commencement of the recordings. The conversations were recorded with a Crown Sound Grabber II PZM Condenser Microphone connected to an Olympus digital voice recorder and placed in the middle of the table around which they sat. They were left in the room and no other person, including the researcher, was present. The quietness of the room was to enable the microphone to capture only the voices of the participants, and not any outside noise. This also ensured that high-quality recordings were obtained. Each recording session lasted 20 minutes. In total, 6 hours 10 minutes of data were obtained from all 40 groups. It must be emphasized that because this is a qualitative study, the focus is more on the data obtained and not necessarily the number of participants.

\subsection{Data analysis}

This study is part of a larger project that seeks to describe the discoursal functions of intonation in Ghanaian English. All the data were subjected to auditory and acoustic analysis; for the auditory analysis, the sound files were played back in order to listen and type word-for word, taking note of pauses, tone unit boundaries, and prominent syllables. After this, the data were transferred onto the computerized speech laboratory (CSL) for the acoustic analysis. With the CSL, the data were segmented into tone units using Brazil's criteria. Although there is no fixed rule as to how to demarcate the boundaries of tone units, certain phonetic criteria, where present, were used to segment one tone unit from the other. These were a) coherent contour, b) [pitch] reset, c) pause (typically between two units), d) anacrusis, and e) [syllable] lengthening (DuBois et al, 1992, p. 100). One advantage of Brazil's model is that while it recognizes the presence of phonetic criteria in signaling tone unit boundaries, it does not require the precise recognition of these boundaries due to the fact that the proclitic and enclitic segments do not carry any linguistically significant contrasts. In effect, this is one of the advantages of Brazil's model in the sense that any phonetic feature such as pitch movement, or pause, or coherent contour can be used to identify tone unit boundaries. Due to this, incomplete and complete tone units with 
multiple prominent syllables were present in the data and these are recognized by Brazil (1997, pp. 14-16).

After tone unit segmentation, the pitch (or fundamental frequency) values were measured for all prominent syllables. The pause durations were measured and the tones were also indicated. Following the analysis, tests of transcriber reliability were conducted using a second transcriber to ensure the quality of the transcription with regard to proper identification of tone units, including properly-marked prominent syllables, and the correct identification of tones. With this, the transcriptions were subjected to rigorous checking and re-checking to ensure reliability, and in consonance with other studies of similar nature (c.f. Cheng et al, 2008), samples of the transcription (20 per cent) were cross-checked by a trained phonetician who has over 20 years' experience working with the systems within Brazil's framework to establish inter-rater reliability. The agreement rate was 97 per cent, and where there were disagreements, they were resolved after some discussions.

\section{Results and Discussion}

\subsection{Prominence selection}

The analysis revealed that prominence is used similarly to the systems proposed in Brazil's model (i.e. in selecting meaning) and different from what might be expected. The sections that follow present instances where Ghanaian English speakers used prominence similar to the proposed systems in the model and follow with a discussion of ways that present an exception or difference to the systems in the model.

\subsubsection{Prominence and meaning selection}

It has already been established in this paper that prominence is mainly marked by speakers to draw listeners' attention to serve the communicative value or the purpose for using any particular piece of language. That is, speakers would normally select particular words or syllables that mostly contribute to the message they wish to communicate. These selcetions were made in the areas of new information, contrastive focus, and end-stress. In this section, the ways speakers of Ghanaian English mark prominence to reflect actual meaning selection similarly to the systems within Brazil's model are discussed:

\subsubsection{Prominence and new information}

The concept of new/given information falls under the purview of information status. Gut, Pillai and Mohd Don (2013) explains information status as "the relationship between individual parts of an utterance and the discourse context in which they are produced, referring to both the participants' attentional states and the status of the discourse content" (p. 186). Typically, high pitch accent has been found to be the standard pitch accent associated with new information in English (e.g. Pierrehumbert \& Hirschberg, 1990). The analysis showed that speakers of Ghanaian English selected prominence to project new information. For example, Figure 1 illustrates the use of prominence to project new information: 
$1 / /$ during our TMES in the primary and jss teachers $/ /$

$2 / /$ Even in those times // e- the teachers are being $\underline{\mathrm{PAD}}$

3 even $/ /$ MEAger salaries $/ /$ but they have they TAKE

4 their $\underline{\mathrm{TME}} / /[0.50] / /$ to $\underline{\mathrm{TEACH}} / /$

Figure 1: An Utterance from Speaker 1

In Figure 1, Speaker 1 narrates the attitude of his teachers during his primary and junior high schools days. Prior to his turn, the group had lamented the low income levels of Ghanaian teachers and their effects on productivity. The previous speaker had suggested that the government should pay teachers well because that is the only way they will work hard. At that point, Speaker 1 takes the floor and gives a narration of how hard his teachers worked though they were paid meager salaries. As speaker 1 considers this information as new to his colleagues, he marks prominence on the syllables times, even, paid, meager, time and teach to communicate that these parts of the utterances are not shared between him and his colleagues. For instance, time is a temporal notion which can be equated to when they were were in the junior high school, while even, paid and meager all relate to the kind of salary that his teachers were receiving at that time. Finally, time and teach refer to how devoted his teachers were to their job. In summary, Speaker 1's meaning can be glossed as: even though our teachers received meager salaries during our junior high school days, they still devoted a lot of their time to their teaching.

Another use of prominence to project new information is seen in Figure 2: Prior to the conversation in Figure 2, participants discussed the senior high school (SHS) duration and its financial impact on parents and students. One speaker said that a student needs much money to be able to sustain him/herself. At this point, speaker 1 takes the floor and tells the group of how she struggled to complete her SHS education. As expected with new information, she chooses the tonic syllables to signal it. In her first tone unit, the speaker assigns prominence to more as opposed to father, suggesting that the listeners would concur with the expectation that it was her father who usually paid her school fees, and the possible unexpected information that he is deceased.

$$
\begin{aligned}
& 1 / / \text { MY father is no MORE } / /[0.31] / / \text { befo- before i went to } \\
& 2 \text { before i started SCHOOLing // [0.64]// my MOther too //[0.30] } \\
& 3 \text { // SHE'S an she's OLDlady } / / b[0.22] / / \text { she can't WORK// [0.51] }
\end{aligned}
$$

Figure 2: An utterance from Speaker 2

In her next tone units, she indicates new information by choosing schooling, mother, old and work. For instance, she chooses mother to communicate that it is her mother she is referring to, in contrast with her reference to her father in the previous unit. Her choice of old and work is also 
used to indicate her mother's age and the fact that she cannot work, as opposed to being young and working.

\subsubsection{Prominence and contrastive focus}

In marking prominence to communicate contrast focus, speakers selected some contrasting items similarly to what pertains with inner circle speakers. Kiss (1998) defines contrastive focus as a notion that "represents a subset of the set of contextually or situationally given elements for which the predicate phrase can potentially hold; it is identified as the exhaustive subset of this set for which the predicate phrase actually holds" (p. 245). In another instance, Krifka (2008) observes that for focus to be contrastive there must be a set of alternatives that is relevant in its interpretation. This means that we can only show contrast if the entities to be contrasted are alternatives and are relevant as well. Figure 3 shows the selection of prominence to mark contrastive focus:

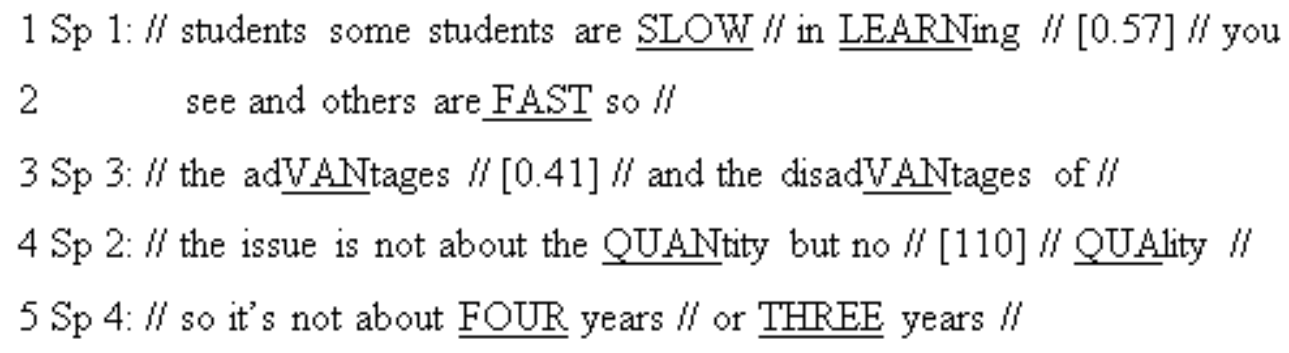

Figure 3: A conversation among speakers

In Figure 3, we notice that each of the speakers selects prominence on both contrasting elements. For instance, Speaker 1 contrasts slow with fast; Speaker 3 contrast advantages with disadvantages; Speaker 2 contrasts quantity with quality, and Speaker 4 contrasts four with three. In all of these, we realize that the elements reflect their functions as contrasting issues within the discourse. Within the context of interaction, as outlined by Brazil (1997), speakers have to package their information so that their listeners can understand them. This is exactly what these four (4) speakers have done. They aligned each of the elements side-by-side to each other to show the contrast (Tomlin et al, 1997). This is similar to what might be expected in native Englishes, an indication that because they elements have been treated in accordance with their information status, it would be easy for their listeners to understand the way information has been packaged as the pragmatic function is clearly conveyed.

\subsubsection{Prominence and end-stress}

According to Gut (2005) and Jowitt (2000), end-stress is the phenomenon whereby the nuclear stress is placed on the last word or syllable in a tone unit. Typically, prominence is marked on content words; nouns, adjective, most verbs, and most adverbs, because they words are said to have meaning. Content words are meaningful as they form the key words of the sentence or utterance. This makes them important so that once they are removed, the sentence or utterance may be difficult to understand or may not make sense. In the data analysis, speakers were seen to mark stress on content words to make meaning, and this is similar to what inner circle speakers 
may expect. These words were the last words in the tone units. Figure 4 contains extracts where speakers properly marked prominence on content words:

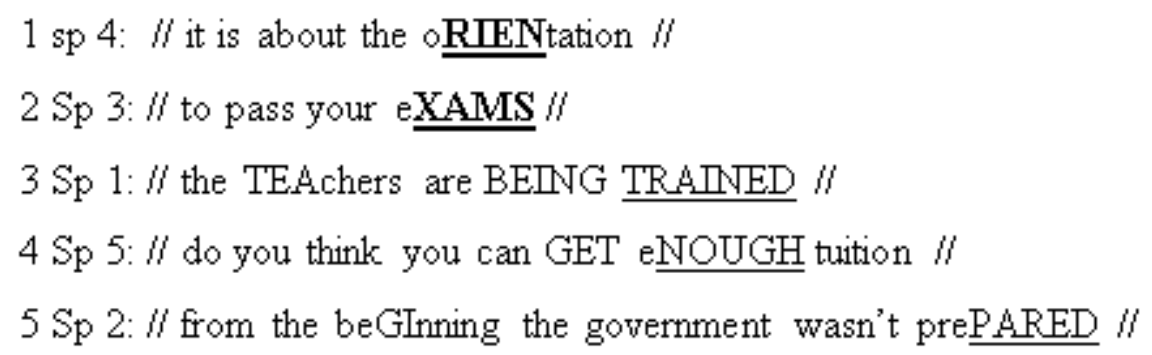

Figure 4: A conversation among speakers

In Figure 4, we notice that all the nuclear syllables carry meaning selections. For instance, in Line 1, Speaker 4 argues that students need orientation when they go to to school in the first term. In her opinion, the orientation will help them to know which programmes to choose and to know how to manage their time. She selects orientation, an indication that she attaches importance to this particular piece of information within the tone unit. Similarly, Line 5 shows the importance Speaker 2 attaches to prepared. Although beginning is also prominent, she assigns prominence to prepared to demonstrate government's preparedness at the introduction of the four-year SHS programme. This tone unit can be rewritten as from the beginning, government wasn't ready, making it easier for the listener to understand that the nuclear syllable prepared is selected on purpose.

\subsubsection{Prominence and non-meaning selection}

Apart from assigning prominence to nuclear syllables to match expectations in inner circle Englishes, speakers were also found to mark some syllables prominent on information that did not appear to be communicatively meaningful. As already indicated, within the context of interaction, interlocutors are expected to make selections that would communicate to one another about a state of affairs. By this token, the selections that speakers make are very crucial in guiding their listeners to understand the message. Unfortunately, it was not always the case that Ghanaian English speakers made this selection. These non-meaning selections were found to have been made in the areas of contrastive focus and end-stress. These are discussed in this section.

\subsubsection{Prominence and non-selection of contrastive focus}

Although Kiss (1998) and Krifka (2008) explain that contrasting element must be marked as relevant alternating entities, it is not always feasible to do so. This is seen in the way speakers of Ghanaian English mark prominence to communicate contrast. In the previous section, we saw that these speakers marked contrast 'appropriately' within the context of interaction. In this section we will also see how they mark prominence on items that do not contrast communicate contrast although they mean to do so. In addition to what we see in Figure 3, speakers also mark contrastive focus in two other ways, although it is not in all cases that they select the actual 
contrasting elements. In fact, they do this in two (2) other ways. Figure 5 illustrates the first instance of non-selection of prominence to show contrast marking:

The extract suggests that the prominence that speakers selected are not communicatively meaningful as far the context of interaction is concerned. For example, in Line 1, Speaker 5 makes a statement that some teachers are lazy. Prior to this conversation, speakers had talked about the fact that most teachers did not attach seriousness to their job when they (the speakers) were in school. They claimed that their teachers were more interested in making money outside of the school. They continued until they got to a point where Speaker 5 produced that utterance. Speaker 2 supported this idea by saying that the teachers were like that because they knew that the duration of their programme four years.

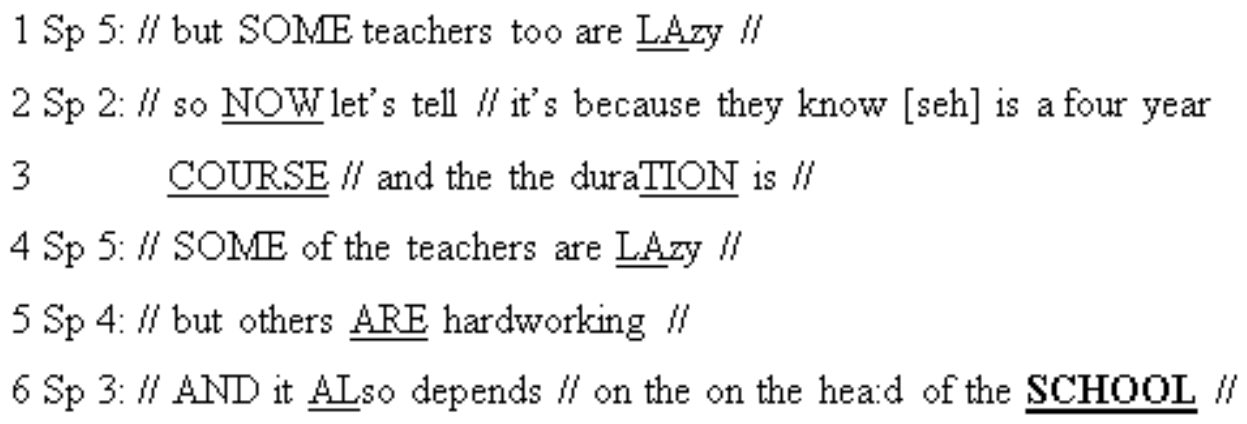

Figure 5: A conversation among speakers

Speaker 5 repeated his utterance and this is where Speaker 4 tried to remind her colleagues that there are some other teachers who are not lazy, but hardworking in Line 5 . We see from this conversation that while Speaker 5 marks prominence on lazy, Speaker 4 marks it on are. Within the context of this interaction, we realize that all that Speaker 4 tries to do is to counter or contrast Speaker 5's statement; yet, she does not mark this contrast on hardworking. The contrast is between lazy and hardworking; however, the way Speaker 4 selects prominence ordinarily makes it difficult for any English speaker to understand it. With this selection, the pragmatic intentions of the speaker may be obscured and this may render the information difficult to process.

Another way by which they do not select prominence to show contrast is shown in Figure 6. In Figure 6, speakers' utterances suggest that they wish to communicate contrast, yet their nuclear syllable selections do not match the intent. For instance, four and three, government and private, and electives and core are the foci of contrast. However, these words are not selected. For instance, in Lines 1 and 2, duration can only be communicated in terms of numbers; and while the contrast is between three and four, we expect the speaker to select them as such. Rather, he selects years when the contrast is not between for example, years and months, days, or weeks. Similar instances are found in Lines 3,4, and 5. The contrast is between government and private on one hand and electives and core on the other hand. 
$1 \mathrm{Sp} 4: / /$ in case you don't know the four YEARS $/ /$ is better than the three

$2 \quad \underline{\mathrm{YEARS}} / /$

$3 \mathrm{Sp}$ 2: // there's some government schools that are doing MUCH $\mathrm{MORE} / /$

4 BEtter than far far better than the private schools //

$5 \mathrm{Sp} \mathrm{3://with} \mathrm{this} \mathrm{students} \mathrm{perform} \mathrm{BEtter} \mathrm{in} \mathrm{the} \mathrm{electives} \mathrm{than} \mathrm{the} \mathrm{the} \mathrm{core} \mathrm{//}$

Figure 6: A conversation among speakers

In Figure 5, we saw that at least one of the contrasting items was selected; in Figure 6, nothing like that happens and so although the speakers wish to communicate contrast, there is contrasting entity selected. While years, more, and better may be communicatively significant, they do not carry any meaning within the context of interaction. Thus, just as indicated in Figure 5, such selections may make information processing a difficult ask for the listener. These examples suggest that speakers' selection of such nuclear syllables show an exception to the systems proposed in Brazil's model.

\subsubsection{Prominence and end-stress}

It has been discussed in the previous section that the way speakers select prominence results in end-stress. It has also been indicated that end-stress in inner circle Englishes typically occurs with content words because they are meaningful. In contrast to content words, speakers can also select function words. Function words include pronouns, prepositions, articles, auxiliary verbs and modal verbs. Regarding their use, their meaning is usually explained grammatically. That is, they need to rely on the entire structure to make meaning. As we would notice in the analysis, speakers of Ghanaian English select both content and function words as the last word in the tone unit. An example is illustrated in Figure 7 as follows:

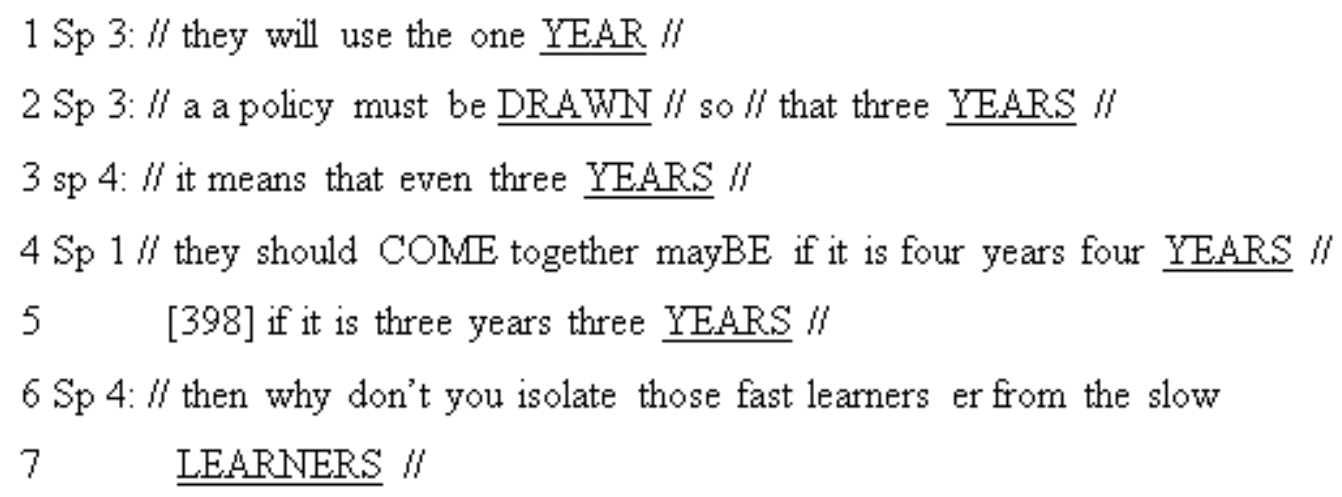

Figure 7: A conversation among speakers

In Figure 7, we see that speakers have selected prominence on the last words in the tone units, resulting in end-stress. We also notice that they have marked prominence on content words; however, these words are not communicatively relevant within the context of interaction. This is because speakers have not selected the words, they need to make meaning. For example, 
in Lines 1-4, speakers have marked prominence on year or years. Since it is duration that is being talked about as the main topic in this study, it is expected that they would focus on either three or four and not years. In fact, neither of these two is selected, an indication that speakers appear to dwell more on years than on the actual number of the years. These particular tone units focus on how many? than on of what?. Another instance of this is seen Lines 6-7 where the speaker marks prominence on learners. Again, although learners is a content word, that is not the main intention of the speaker. We notice that there is a long tone unit that contrasts fast with slow, and yet, neither word is selected. We clearly see that there is no contrast communicated here because of the selection made.

While content words may be selected non-communicatively, there are more instances where speakers select function words in place of content ones. An example is shown in Figure 8;

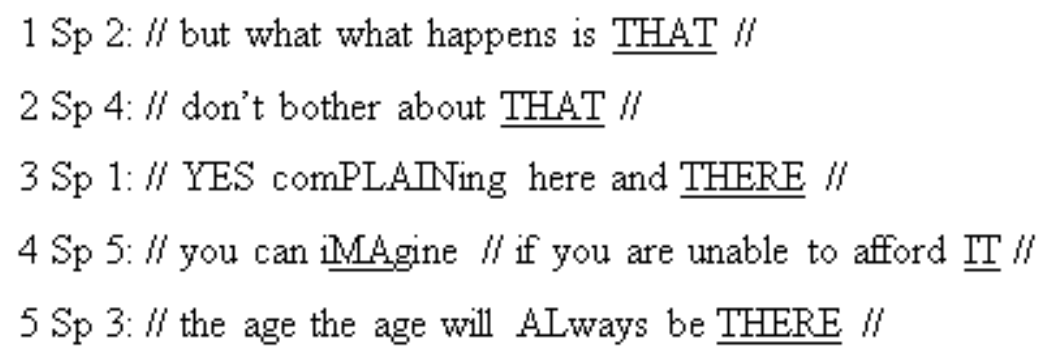

Figure 8: A conversation among speakers

In Figure 8, we notice instances of end-stress in five (5) of the six (6) tone units. In all these five tone units, we see that prominence falls on the last words which are function words. Typically, these words do not communicate any meaning considering the context of interaction, an indication that prominence selection here does not conform to what is expected within the systems proposed in Brazil's. For instance, in Line 1, the selection would have been made on happens; it would have been made on bother in Line 2; on complaining in Line 3; afford in Line 4, and age in Line 5. However, this is not the case, an indication that prominent syllables may or may not indicate a meaning selection in this English variety.

\subsection{Prominence and meaning selection in outer circle Englishes}

The first research question focused on examining how speakers of Ghanaian English mark prominence in speech to convey their communicative intentions. The results suggest that prominence is selected; however, their selection may or may not indicate a meaning selection. The results show that prominence is marked 'appropriately' to project new information, to communicate contrast, and to indicate end-stress on meaningful words. This is in conformity with what is proposed in Brazil's model and what might be expected by the inner circle listener. This selection confirms the assertions of Levis \& Muller Levis, (2020), Muller Levis, Levis and Benner (2014), and Baumann and Winter (2018) that English speakers use prominence to mark contrast, project new information and to mark end-stress on content words. On the other hand, speakers selected prominence on words that do not communicate any meaning within the specific context of interaction. This is seen in the way they mark contrastive focus and end-stress 
on function words and non-communicative content words. This is where they differ from how prominence selection is done in inner circle Englishes and the functions of the systems proposed in discourse intonation.

The second research question sought to determine how prominence is selected to communicate meaning in outer circle Englishes. It is important to note that the way prominence is selected in Ghanaian English is not different from what pertains in other outer circle varieties. This means that speakers in this circle have a common destiny. For example, Goh (2005), Jowitt (2000), and Low and Brown (2005) note that their Singaporean, Malaysian, and Nigerian participants marked prominence similarly to what the inner circle speaker would produce and different as well. Almost all these researchers indicate that there are studies that claim that the difference in the way prominence is selected might lead to some misunderstanding if they communicate with inner circle listeners who might expect to hear specific selections. In terms of our common destiny, there are other pronunciation features that are shared by outer circle speakers of English. These include Absence of/almost no-production of reduced vowels (Deterding, 2011), consonant cluster simplification (Gut, 2007), and substitution of some consonants (Deterding \& Kirkpatrick, 2006).

From the data analysis, we realize that whether speakers selected prominence to communicate meaning or not, there were no instances of misunderstanding among them. This is because we did not encounter any situations where interlocutors stopped one another for clarification or explanation, an indication that their pragmatic intentions were well-received and understood. This also means that while we recognize the importance of prominence selection, "it may indicate meaning selection for one speaker but not so for others" (Deterding, 2013, p. 79). In addition, in situations where the selections are similar, speakers may designate different discourse roles to such selections. Based on such arguments, Deterding further observes that the same rules that apply to prominence in inner circle Englishes may not apply to other varieties. It is thus argued that once interlocutors can understand one another, then, there is no need to see them as following a deficit model, but rather, be seen as having a difference model as legitimate speakers of the language. Because most inner circle speakers consider outer circle speakers as having a deficiency, Levis (2005) believes that they are yet to be fully seen as "native speakers" ( $p$ 86). It is also note-worthy that outer circle speakers mainly communicate with one another, mostly without any inner circle speakers. This means that as legitimate users and owners of the language, we do not need to produce phonological features to 'suit' someone's ears, but we need to communicate for intelligibility. The analysis showed that speakers' pronunciation sounded intelligible to one another. That way, there is no need to mimic someone and make mistakes as long as you are understood.

\section{Conclusion}

With data from 100 participants subjected to auditory and acoustic analyses, the present study has answered questions regarding the use of prominence to convey communicative intentions in Ghanaian English as well as the role of prominence in meaning selection in outer circle Englishes. The analysis showed that select prominence; however, this may or may not indicate a meaning 
selection in this English variety, and by extension, other outer circle English varieties. The results point to a lot of implications. We need to recognize that apart from the outer circle, speakers within the expanding circle also have similar pronunciation tendencies (see Deterding \& Kirkpatrick 2006; Verdugo Ramirez, 2002); however, this paper focus only on prominence selection in Ghanaian English and its relation to other outer circle Englishes.

From the discussion, we realize that for outer circle speakers to be seen as owners of their pronunciation features and the English varieties they speak, a common model that focuses on difference, not deficiency, has to be developed for them. This is because they can sufficiently be considered native speakers in their right and not a group of people who rely on some other speakers to provide them a norm to follow. This also implies that the native speaker is no longer the yardstick for English pronunciation. This is captured succinctly by Graddol (1997) who describes the "decline of the native speaker" and recognizes that "(...) those who speak English as a second or foreign language will determine its world future" (p. 10). Hence, "English belongs to all who use it" and that "norms and standards should no longer be determined by Inner Circle/ENL contexts" (Schneider, 2003, p. 237). Tying this to pronunciation, Low (2015) states that "the communication function of intonation varies across different speakers of English and across different cultures" (p. 125). Prominence is an aspect of intonation and so Low's assertion applies to the function of prominence as well.

Taken together, the adoption of Brazil's discourse intonation model has shown that while it was originally proposed with inner circle data, it can actually be applied to varieties outside this circle. The present study adds to existing literature as far as discourse intonation is concerned and also documents the discovery of new facts common to outer circle speakers. It can therefore be concluded that with the differences outlined and for Brazil's model to accommodate there is the need to modify it to suit these varieties. In addition, the differences across these varieties should be recognized as systematic and established. After all, intelligibility is key to communicating in English (Jenkins, 2000); as such, listeners may have to rely on other cues such as the lexical items in addition to the phonological cues to comprehend one another's utterances.

\section{Transcription conventions}

With a few exceptions, all the transcriptions follow Brazil's transcription conventions. These have been summarized as follows:

$\begin{array}{ll}\text { Pause unit boundaries } & / / / / \\ \text { Pitch Sequence boundaries } & \text { ///// } \\ \text { Onset syllables } & \text { UPPERCASE } \\ \text { Nuclear syllable } & \text { UPPERCASE } \\ \text { Length of pause } & {[]} \\ \text { Lengthening } & ::\end{array}$

\section{Conflict of Interest Statement}

The author declares no conflicts of interests 


\begin{abstract}
About the Author
Charlotte Fofo Lomotey is a Senior Lecturer of Applied Linguistics and ESL at the University of Education, Winneba. She holds a PhD in English with emphasis on Applied Linguistics from the Texas A\&M University, Commerce, USA. Her research interests are in the areas of Prosody and Discourse, Second Language Phonology, Current Issues in Teaching ESL, Classroom Discourse, and The Phonology of English as a Lingua Franca.
\end{abstract}

\title{
References
}

\section{Journal articles}

Baumann, S. \& Winter, B. 2018. What makes a word prominent? Predicting untrained German listeners' perceptual judgments. Journal of Phonetics, 70, 20-38.

Clark, H. H. 2001. Conversation: Linguistic Aspects. In N. J. Smelser \& P. B. Baltes (Eds.), International Encyclopedia of the Social \& Behavioral Sciences (pp. 2744-2747). Elsevier Ltd.

Clark, H. H. \& Schaefer, E. F. 1989. Contributing to discourse. Cognitive Science, 13, 259-294.

Deterding, D. 2011. English language teaching and the lingua franca core in East Asia. In W.-S. Lee \& E. Zee (Eds.), Proceedings of the 17th International Congress of Phonetic Sciences (pp. 92-95). City University of Hong Kong.

Deterding, D. \& Kirkpatrick, A. 2006. Emerging South-East Asian Englishes and intelligibility. World Englishes, 25(3/4), 391-409.

Goh, C. 2001. Discourse intonation of English in Malaysia and Singapore: Implications for wider communication and teaching. RELC Journal, 32(1), 92-105.

Gut, U. 2005. Nigerian English prosody. English World-Wide 26, 153-177.

Gut, U. 2007. First language influence and final consonant clusters in the new Englishes of Singapore and Nigeria. World Englishes, 26(3), 346-359.

Gut, U., Pillai, S., \& Mohd Don, Z. 2013. The prosodic marking of information status in Malaysian English. World Englishes, 32(2), 185-197.

Hahn, L. 2004. Primary stress and intelligibility: Research to motivate the teaching of suprasegmentals. TESOL Quarterly, 38(2), 201-233.

Hewings, M. 1995. Tone choice in the English intonation of non-native speakers. International Review of Applied Linguistics, 33(3), 251-265.

Jowitt, David. 2000. Patterns of Nigerian English intonation. English World-Wide, 21, 63-80.

Kiss, K. É. 1998. Identificational focus versus information focus. Language, 74(2). 245-273.

Krifka, M. 2008. Basic Notions of Information Structure. Acta Linguistica Hungarica 55(3-4). 243276.

Ramirez Verdugo, D. 2002. Non-native interlanguage intonation systems: A study based on a computerized corpus of Spanish learners of English. ICAME Journal, 26, 115-132.

Samuelsson, C. 2009. Using conversation analysis to study prosodic problems in a child with language impairment. Child Language Teaching and therapy, 25(1), 59-88.

Schneider, E. W. 2003. The dynamics of new Englishes: From identity construction to dialect birth. Language, 79(2), 233-281. 
Warren, P., Elgort, I. \& Crabbe, D. 2009. Comprehensibility and prosody ratings for pronunciation software development. Language Learning $\mathcal{E}$ Technology, 3(3), 87-102.

\section{Books}

Brazil, D. 1994. Pronunciation for advanced learners of English. Cambridge University Press.

Brazil, D. 1997. The communicative value of intonation in English. Cambridge University Press.

Brazil, D., Coulthard, M., \& Johns, C. (1980). Discourse intonation and language teaching. Longman.

Brazil, D. 1978. Discourse intonation II. English Language Research Monographs.

Brazil, D. 1985. The communicative value of intonation. English Language Research.

Brazil, D. 1995. A grammar of speech. Oxford University Press.

Cauldwell, R. 2007. The reliability of intonation transcriptions: Implications for speech corpora. SpeechinAction Research Centre (SPARC).

Cauldwell, R., \& Allen, M. 1999. Phonology. Birmingham: The University of Birmingham.

Cheng, W., Greaves, C., \& Warren, M. 2008. A Corpus-driven Study of Discourse Intonation. John Benjamins.

Coulthard, M. (Ed.). 1994. Advances in written text analysis. Routledge.

Creswell, J. W. 2012. Qualitative inquiry \& research design: Choosing among five approaches (4th edn.). SAGE.

Crystal, D. 1969. Prosodic systems and intonation in English. Cambridge University Press.

Dalton, C., \& Seidlhofer, B. 1994. Pronunciation. Oxford University Press.

Denzin, N. K. \& Lincoln, Y. S. (Eds.). 2018. The SAGE handbook of qualitative research. SAGE.

Deterding, D. 2013. Misunderstandings in English as a Lingua Franca: An analysis of ELF interactions in South-East Asia. De Gruyter

Graddol, D. 1997. The future of English? A guide to forecasting the popularity of the English language in the 21st century. British Council.

Halliday, M. A. K. 1970. A Course in Spoken English: Intonation. Oxford University Press.

Jenkins, J. 2000. The phonology of English as an international language. Oxford University Press.

Kachru, B. B. 1986. The alchemy of English: The spread functions and models of non-native Englishes. Pergamon.

Low, E. L. 2015. Pronunciation for English as International Language: From research to practice. Routledge.

Low, E. L. \& Brown, A. 2005. English in Singapore. An Introduction. McGraw-Hill.

Sinclair, J. M. H. \& Brazil, D. 1982. Teacher talk. Oxford University Press.

Sinclair, J. M. H. \& Coulthard, R. M. 1975. Towards an analysis of discourse: The English used by teachers and pupils. Oxford University Press.

Tench, P. 1996. The Intonation Systems of English. Cassell.

Yin, R.K. 2009. Case study research: Design and methods (4th edn.). SAGE.

\section{Book chapters}

Du Bois, J. W., Schuetze-Coburn, S., Paolino, D., \& Cumming, S. 1992. Discourse

transcription. In S. A. Thompson (Ed.), Santa Barbara papers in linguistics (vol. 4). University of California, Santa Barbara. 
Goh, C. C. M. 2000. A discourse approach to the description of intonation in Singapore English. In A. Brown, D. Deterding \& E. L. Low (Eds.), The English Language in Singapore: Research on Pronunciation (pp. 35-45). Singapore Association for Applied Linguistics.

Low, E. L. 2000. Is lexical stress placement different in Singapore English and British English? In D. Deterding, A. Brown \& E. L. Low (Eds.), The English Language in Singapore: research on pronunciation (pp. 22-34). Singapore Association for Applied Linguistics.

Muller Levis, G., Levis, J. M. 2020. Teaching contrastive stress for varied speaking levels. In

O. Kang, S. Staples, K. Yaw, \& K. Hirschi (Eds.), Proceedings of the 11th Pronunciation in Second Language Learning and Teaching conference, (pp. 316-325). Iowa State University.

Pierrehumbert, J. \& Hirschberg, J. 1990. The Meaning of intonational contours in the interpretation of discourse. In P. R. Cohen, J. Morgan \& M. E. Pollack (Eds.), Intentions in Communication (pp. 271-311). MIT Press.

Selkirk, E. 2002. Contrastive FOCUS vs. presentational focus: Prosodic evidence from right node raising in English. In Bel Bernard \& Isabelle Marlien (Eds.), Proceedings of the First International Speech Prosody Conference (pp. 643-646). Laboratoire Parole et Langage.

Terken, J., \& Hermes, D. 2000. The perception of prosodic prominence. In M. Horne (Ed.), Prosody: Theory and experiment. Studies presented to Gösta Bruce (pp 89-127). Springer.

Tomlin, R. S., Forrest, L., Ming, M. P. \& Myung, K. 1997. Discourse semantics. In Teun van Dijk (Ed.), Discourse as structure and process (Discourse studies: A multidisciplinary introduction 1), (pp. 63-112). Sage Publications.

\section{Conference Presentation}

Muller Levis, G., Levis, J., \& Benner, S. 2014. Contrastive stress can be learned - But can it be taught at lower levels? Paper given at the Pronunciation in Second Language Learning and Teaching. Iowa State University. 

or adapt the article content, providing a proper, prominent and unambiguous attribution to the authors in a manner that makes clear that the materials are being reused under permission of a Creative Commons License. Views, opinions and conclusions expressed in this research article are views, opinions and conclusions of the author(s). and European Journal of Literature, Language and Linguistics Studies shall not be responsible or answerable for any loss, damage or liability caused in relation to/arising out of conflicts of interest, copyright violations and inappropriate or inaccurate use of any kind content related or integrated into the research work. All the published works are meeting the Open Access Publishing requirements and can be freely accessed, shared, modified, distributed and used in educational, commercial and non-commercial purposes under a Creative Commons Attribution 4.0 International License (CC BY 4.0). 